\title{
Development of a Methodology to Determine Antibiotic Concentrations in Water Samples Using High-Pressure Liquid Chromatography
}



Tahnee Qualls $^{1 *}$, Carmen Agouridis ${ }^{1}, \&$ Manish Kulshrestha ${ }^{1}$

Antibiotic concentrations are typically measured using solid-phase extraction along with liquid chromatography, but this process is not practical due to a large number of man hours involved. The use of a lyophilizer with high-pressure liquid chromatography (HPLC) is an accurate and cost-effective method of analyzing antibiotics in water samples. An initial antibiotic analysis methodology was developed with the goal of concentrating antibiotics in water samples for greater detection; however, it was observed that the methodology required additional refinement to improve accuracy, particularly when manure was present in the water samples. Based on prior tetracycline antibiotic research, we hypothesized that sample preparation techniques and HLPC characteristics would influence our ability to detect these antibiotics in water samples. We anticipated that analysis of larger sample volumes would improve antibiotic detection while higher manure concentrations would decrease detection capabilities. The objective of this study was to examine the effects of a secondary sample preparation step (filtration), mobile phase solution, HPLC column, sample volumes, wavelengths, and manure concentrations on the recovery rates of three common antibiotics, specifically chlortetracycline (CTC), tetracycline (TC), and oxytetracycline (OTC). The study examined three filtration methods, two mobile phase solutions, two HPLC columns, five sample volumes, three wavelengths, and four manure concentrations. Best results were obtained with a mobile phase solution of acetonitrile with $0.05 \%$ formic acid, the Acclaim ${ }^{\circledR}$ RSLC C18 PA2 column, smaller sample volumes, and a wavelength of $356 \mathrm{~nm}$. This study highlighted some of the challenges associated with detecting antibiotics in water samples. The accurate detection of antibiotics in water samples is an important step in developing and testing methods to reduce antibiotic transport in the environment.

\section{INTRODUCTION}

The U.S. Environmental Protection Agency (USEPA) classifies antibiotics as a contaminant of emerging concern (CEC) because they are detected in the environment at higher than expected levels and may negatively impact human and aquatic ecosystems (USEPA, 2013). The risk these antibiotics pose to humans and aquatic life is not known; however, the primary concern is that the antibiotic-resistant strains of bacteria will develop. Utilization in human healthcare and livestock care are the two main sources of antibiotics in the environment. Unlike human waste, which is treated via treatment plants or septic systems, livestock waste is oftentimes directly applied to the land as part of a nutrient management plan (NRCS, 2012). Baguer, Jensen, and Krogh (2000) noted that land

\footnotetext{
${ }^{1}$ University of Kentucky, Biosystems and Agricultural Engineering Department, 128 C.E. Barnhart Building, Lexington, KY 40546-0276

*To whom correspondence should be addressed: carmen.agouridis@uky.edu

Except where otherwise noted, this work is licensed under https://creativecommons.org/licenses/by-nc-nd/4.0/

doi:10.22186/jyi.33.1.19-27
}

application of manure is the main pathway for veterinary antibiotic introduction into the terrestrial and aquatic environments. In agriculture, antibiotics are used for both therapeutic as well as non-therapeutic purposes. The two main non-therapeutic uses of antibiotics in livestock are growth additives and illness prevention (Shore, \& Pruden, 2009). Estimates are that 11 million $\mathrm{kg}$ of antibiotics were used in 2002 along for non-therapeutic uses (Davis et al., 2006). Unfortunately, large amounts of administered antibiotics are not metabolized by animals but instead are excreted in manure. Rates of unmetabolized antibiotics are as high $70-90 \%$ as in the case of tetracyclines, which are one of the most used classes of antibiotics (Kumar Gupta, Chander, \& Singh, 2005; USEPA, 2013).

Manures are commonly applied across croplands as part of farm nutrient management plans. Hence, the antibiotics in these manures are land applied as well. Once applied to the land, antibiotics are transported to surface waters, via runoff, or ground waters, through infiltration. To date, only a limited amount of research has been conducted on the transport of antibiotics in the runoff, but this research indicates that the mechanisms of transport vary with antibiotic type. Some antibiotics bind to and are transported with soil, while others do not (Tolls, 2001). Limited studies have examined the use of best management practices (BMPs), such as vegetated filter strips, and the addition of alum to minimize antibiotic transport (Enlow, 2014; DeLaune, \& Moore, 2013; Lin et al., 2011). 
One challenge, in studies involving antibiotics, is the sensitivity and reliability of the methods used to detect the antibiotics. Another is the time required, and hence labor costs, associated with performing antibiotic analyses. Because antibiotic concentrations are so low, they require concentration before extraction. Typically, solid-phase extraction is used along with liquid chromatography. However, when a study requires analyzing many samples, solidphase extraction is impractical due to the high amount of human labor involved. To address this issue, Enlow (2014) developed a methodology using a lyophilizer for use in the analysis of the antibiotic oxytetracycline. The lyophilizer was used to concentrate antibiotics in water samples with the goal of improving antibiotic detection. Results indicated the methodology worked well at high oxytetracycline concentrations but performed somewhat poorly at low levels in the presence of manure. The poorer performance was due to the presence of one or more unknown constituents which appeared on the chromatograph near the peak of chlortetracycline. Enlow (2014) hypothesized that a secondary filtration step, larger sample volumes, and different wavelengths on the HPLC would improve antibiotic recovery rates. These assumptions were made based on the presence of visible solids in samples following one filtration, which was thought to interfere with antibiotic detection, total suspended solids methodology, which uses larger sample volumes to improve accuracy in the presence of low concentrations (Eaton et al., 1998), and a subsequent literature review which identified the use of a range of wavelengths to measure tetracycline antibiotics (personal communication). Wavelengths are significant to the determination of the substance in a sample because different compounds absorb different wavelengths of UV light (Kay, Blackwell, \& Boxall, 2005). Questions regarding the effects of different manure concentrations, in water samples, on antibiotic recovery rates remained, as did the effects of different mobile phase solutions and HPLC columns.

Based on prior tetracycline antibiotic research, we hypothesized that sample preparation techniques, namely an additional filtration step to remove remaining particulates that can interfere with HPLC performance (CDER, 1994), and HLPC characteristics, such as mobile phase solution (Jia, Xiao, Hu, Asami, \& Kunikane, 2009), column type (Ritorto et al., 2014) and wavelength (Ng, \& Linder, 2003), would influence antibiotic detection in water samples. We anticipated that analysis of larger sample volumes would improve antibiotic detection, as we would have a more material from which to develop a concentrate, while higher manure concentrations would decrease detection capabilities due to the presence of more impurities requiring removal to not inhibit HPLC performance. This study aimed to examine the effects of a secondary sample preparation step (filtration), mobile phase solution (mobile phases), HPLC column, sample volumes, wavelengths, manure concentrations on the recovery rates of three common antibiotics, specifically chlortetracycline (CTC), tetracycline (TC), and oxytetracycline (OTC). The laboratory analyses were first conducted and refined on manure-free samples prior to examining samples with manure.

\section{MATERIALS AND METHODS}

\section{Antibiotics}

Three commonly used antibiotics were examined: CTC, TC, and OTC. Antibiotics (chlortetracycline hydrochloride $\geq 75 \%$ HPLC; tetracycline hydrochloride $\geq 95 \%$ European Pharmacopeia HPLC assay; oxytetracycline hydrochloride $\geq 95 \%$ (HPLC) crystalline) were obtained from Sigma-Aldrich (St. Louis, Mo.). These antibiotics were evaluated at concentrations of 1, 10, 20, 100 and 200 $\mu \mathrm{g} / \mathrm{mL}$. Additionally, an equal combination of the three antibiotics (COMBO) was examined at final concentrations of 1, 10, 20, 100 and $200 \mu \mathrm{g} / \mathrm{mL}$ (individual antibiotic concentrations of 0.33 , $3.33,6.67,33.3,66.7 \mu \mathrm{L} / \mathrm{mL}$, respectively, were used to create COMBO).

\section{Secondary Sample Preparation Step (Filtration)}

Three sample preparation methods were examined: solid-phase extraction (SPE), lyophilization (LYO), and a combination of the SPE and lyophilization (BOTH). Prior to SPE, samples were centrifuged for 10 minutes at 1500RPM using a Thermo Scientific Sorvall Legend XTR Centrifuge. Three replications of all antibiotics (CTC, TC, OTC, and COMBO) at all five concentrations were used to examine the three filtration methods. One replication was used per filtration method.

In SPE, the sample is manually pulled through a SPE cartridge; it is the SPE cartridge that retains the antibiotics. First, SPE cartridges are preconditioned prior to use with $1 \mathrm{~mL}$ of Methanol(MeOH) followed by $4 \mathrm{~mL}$ of deionized water. Samples are then manually loaded into the SPE cartridges using a $10 \mathrm{~mL}$ syringe at $2 \mathrm{~mL} / \mathrm{min}$, a rate which is quite slow especially for large sample volumes. Next, the SPE cartridge is washed with $0.05 \%$ $\mathrm{MeOH}$ in deionized water. This step is important when analyzing samples containing particulates as they can inhibit sample movement through the cartridges. Finally, the sample is eluted from the SPE cartridge using $2 \mathrm{~mL} \mathrm{MeOH}$. To conduct the SPE, $60 \mathrm{mg}$ bed weight, $3 \mathrm{~mL}$ column volume Thermo Scientific Hypersep Retain PEP was used.

LYO, or freeze drying, instead removes the liquid from a sample to concentrate any remaining constituents. LYO is especially beneficial for large sample volumes as it can greatly reduce their size without impacting constituents in the sample. For the LYO, SP Scientific VirTis Wizard 2.0 lyophilizer (Gardiner, New York) was used.

For the LYO and BOTH filtration methods, two replications were frozen at a temperature of $-44^{\circ} \mathrm{C}$ until the sample was completely solid and then placed in the lyophilizer until all liquid was removed (approximately six days). For the LYO filtration method, samples were rehydrated with $2 \mathrm{~mL}$ of methanol $(\mathrm{MeOH})$ and then analyzed on the A Dionex Ultimate 3000 HPLC along with an Ultimate 3000RS Variable Wavelength detector (Sunnyvale, California) $(0.05 \%$ formic acid in acetonitrile mobile phase solution; RSLC PAC column; wavelengths of 230, 290 and 356nm). For the BOTH filtration method, samples were rehydrated with $5 \mathrm{~mL}$ of deionized water and analyzed via SPE following standard procedures (Sigma-Aldrich, 1998). 


\section{Mobile Phase Solution}

Mobile phase solutions are used with HPLC methodologies to dissolve and transport constituents, improve constituent separation, and maintain $\mathrm{pH}$ as to improve accuracy and precision (Shimadzu, n.d.). Two mobile phase solutions were examined: $0.05 \%$ acetic acid solution in methanol $(\mathrm{MeOH})$ and $0.05 \%$ formic acid $\left(\mathrm{C}_{2} \mathrm{H}_{4} \mathrm{O}_{2}\right)$ in acetonitrile $\left(\mathrm{C}_{2} \mathrm{H}_{3} \mathrm{~N}\right)$. These weakly acidic solutions were chosen for their compatibility with antibiotics extraction from the solid phase to liquid phase (Kim and Carlson, 2007; Suárez, Santos, Simonet, Cárdenas, \& Valcárcel, 2007) and from their prior use in other research focused on HPLC use to evaluate antibiotics (Hernádez, Sancho, Ibáñez, \& Guerrero, 2007; Lindberg, Jarnheimer, Olson, Johansson, \& Tysklind, 2005; Yang, Cha, $\&$ Carlson, 2005). Manure free water samples were spiked with one of three types of antibiotics (CTC, TC, and OTC) to final concentrations of $10,50,100$, and $1000 \mu \mathrm{g} / \mathrm{mL}$ to see how the mobile phase solutions worked with a range of concentrations. Spiked water samples were used to ensure distinctly visible antibiotic peaks on the chromatogram. When examining the influence of mobile phase solution type on antibiotic recovery rates, only the RSLC column was used; however, all three wavelengths examined in this study (section 2.6) were examined.

\section{HPLC Column}

In the HPLC process, the solution passes through a column composed of unique material. The interaction between sample constituents and column material allows for the separation of the constituents as their pass-through rate varies. A Dionex Ultimate 3000 HLPC (Sunnyvale, CA) and an Ultimate 3000RS Variable Wavelength Detector (Sunnyvale, CA) were used. Two HPLC columns were examined: Acclaim ${ }^{\circledR}$ Rapid Liquid Separation Liquid Chromatography (RSLC) C18 Polar Advantage II (PA2) (polar-embedded reversed-phase, $3 \mu \mathrm{m}$ particle size, $2.1 \mathrm{~mm}$ diameter, $150 \mathrm{~mm}$ length, $120 \AA$ average pore diameter) and Acclaim ${ }^{\circledR} 120 \mathrm{C} 18$ (conventional reversed-phase, $3 \mu \mathrm{m}$ particle size, $2.1 \mathrm{~mm}$ diameter, $100 \mathrm{~mm}$ length, $120 \AA$ average pore diameter). The Acclaim ${ }^{\circledR} 120$ $\mathrm{C} 18$ was chosen because of its use in other studies involving tetracycline antibiotics (Enlow, 2014; Haghedooren et al., 2008; Yang et al., 2004; Tong, Wang, \& Zhu, 2009). The Acclaim ${ }^{\circledR}$ RSLC C18 PA2 is a newer column type, so its uses in antibiotic studies is less documented (Bean et al., 2016). As with the mobile phase solution, manure free water samples were spiked with one of three types of antibiotics (CTC, TC, and OTC) to concentrations of 10, 50, 100, and $1000 \mu \mathrm{g} / \mathrm{mL}$.

\section{Sample Volume}

Five sample volumes were examined: 100, 200, 300, 400 and $500 \mathrm{~mL}$. Each sample volume was spiked to create a final OTC concentration of $20 \mu \mathrm{g} / \mathrm{mL}$. This concentration was chosen based on work done in Enlow (2014). Due to budget and time constraints, multiple antibiotics at multiple concentrations were not examined. All samples were frozen for at $-80^{\circ} \mathrm{C}$ and then placed in the lyophilizer for two weeks. Samples were then reconstituted with $2 \mathrm{~mL}$ of
$\mathrm{MeOH}$ and analyzed on the HPLC at $356 \mathrm{~nm}$ using a mobile phase of $0.05 \%$ formic acid in acetonitrile and a RSLC PAC column.

\section{Wavelength}

Three wavelengths $(230,290$ and $356 \mathrm{~nm})$ were examined using water samples with containing $0.01,0.05,0.15$, and $0.25 \mathrm{~g} /$ $\mathrm{mL}$ swine manure that had been spiked with antibiotics (Table 1). Briefly, antibiotic-free swine manure was collected from a nearby small heritage hog farm and transported to the Biosystems and Agricultural Engineering Department at the University of Kentucky and stored at $0^{\circ} \mathrm{C}$ until analysis. Once thawed, antibiotics (CTC, $\mathrm{TC}$, OTC, and COMBO) were added to subsamples at concentrations of 10 and $20 \mu \mathrm{g} / \mathrm{mL}$. For the COMBO samples, equal parts CTC, TC, and OTC were added to the manure to arrive at final antibiotic concentrations of 10 and $20 \mu \mathrm{g} / \mathrm{mL}$. All water samples ( $20 \mathrm{~mL}$ deionized water; $\mathrm{n}=96$ ) were created in triplicate to evaluate the three methods of filtration (SPE, LYO, and BOTH). The small sample volume $(20 \mathrm{~mL})$ allowed for more rapid analysis as it decreased the time required for the filtration process.

Table 1. Manure concentrations for tested water samples.

\begin{tabular}{|c|c|c|c|}
\hline Manure (\%) & $\begin{array}{l}\text { Deionized } \\
\mathbf{H}_{2} \mathbf{O}(\mathbf{m L})\end{array}$ & $\begin{array}{l}\text { Manure } \\
(\mathbf{g})\end{array}$ & $\begin{array}{l}\text { Manure } \\
\text { Concentration } \mathbf{( g / m L})\end{array}$ \\
\hline 1 & 20 & 0.2 & 0.1 \\
\hline 5 & 20 & 1 & 0.15 \\
\hline 15 & 20 & 3 & 0.5 \\
\hline 25 & 20 & 5 & 0.25 \\
\hline
\end{tabular}

\section{Manure Concentration}

The effect of manure concentration $(0.01,0.05,0.15$, and $0.25 \mathrm{~g} /$ $\mathrm{mL}$ ) on antibiotic recovery rate was examined. Wet manure was weighed and then placed in $20 \mathrm{~mL}$ of deionized water and vigorously mixed. An initial antibiotic concentration of $20 \mu \mathrm{g} / \mathrm{mL}$, LYO filtration, Acclaim ${ }^{\circledR}$ RSLC C18 PA2 column, and a wavelength of $356 \mathrm{~nm}$, were used. A secondary filtration step was not used.

\section{Statistical Analysis}

An Analysis of Covariance (ANCOVA) was used to compare the parameters wavelength, antibiotic type, antibiotic concentration, and manure concentration to antibiotic recovery rates (\%) in SAS $(p>.05)$. Both wavelength and antibiotic type served as class (categorical) variables.

\section{RESULTS}

\section{Secondary Sample Preparation Step (Filtration)}

As the antibiotic analysis methodology was first developed on samples without manure, the effects of a secondary sample preparation step (filtration) were not examined until later in the experiment due to funding limitations. The time required to filter the samples was substantial. Filtering one $100 \mathrm{~mL}$ sample required 
nearly one hour. Preliminary results from this study indicated that samples containing large amounts of manure (e.g. $>5 \%$ by volume) will likely require a third filtration step to remove solids before lyophilization. Without this step, a lot of solids remains after lyophilization. Ideally, after lyophilization, the only desired remnants are the antibiotics, which can be easily saturated with a mobile phase solution and tested directly in the HPLC.

\section{Mobile Phase Solution}

When $0.05 \%$ acetic acid in $\mathrm{MeOH}$ was used as a mobile phase solution, the peaks for TC and OTC overlapped while the peak for CTC was distinct (Figure 1). Using $0.05 \%$ formic acid in acetonitrile as the mobile phase solution improved peak separation between the OTC and TC while maintaining the clear distinction in CTC. Thus, $0.05 \%$ formic acid in acetonitrile was used as a mobile phase solution in the remainder of the experiments.

\section{HPLC Column}

Peak separation amongst the antibiotics was better using the Acclaim ${ }^{\circledR}$ RSLC C18 PA2 column as compared to the Acclaim ${ }^{\circledR} 120$ C18 column. Figure 2a shows the clear and symmetric peaks associated with Acclaim ${ }^{\circledR}$ RSLC C18 PA2 column while Figure 2b shows that the peaks associated with the Acclaim ${ }^{\circledR} 120$ column are less distinct.

\section{Sample Volume}

Smaller sample volumes are more efficient to analyze due to lesser times required for filtration. With LYO, for example, large sample volumes can require multiple weeks to dry. Oxytetracycline was evaluated at a concentration of $20 \mu \mathrm{g} / \mathrm{mL}$ in clean, deionized water. Samples were run on the Acclaim ${ }^{\circledR}$ RSLC C18 PA2 column and with a mobile phase solution of $0.05 \%$ formic acid in acetonitrile. Sample volume had no significant effect on antibiotic recovery rates $(\alpha=.05)$ (Table 2$)$.
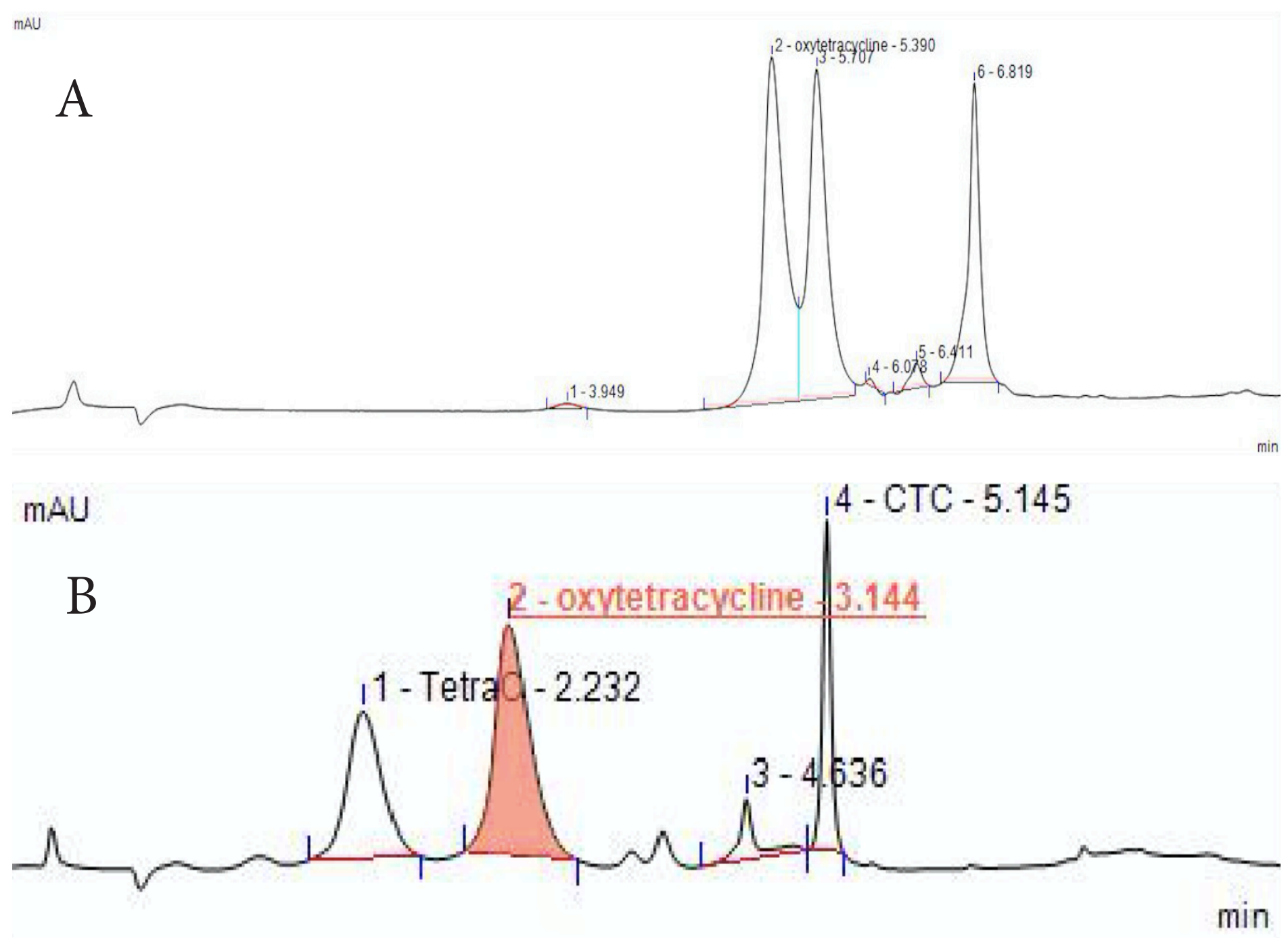

Figure 1. (A) The peaks for oxytetracycline (OTC) and tetracycline (TC) overlap when a MeOH with $0.05 \%$ acetic acid mobile phase solution is used. (B). Using a mobile phase solution of acetonitrile with $0.05 \%$ formic acid, the peaks between TC and OTC are distinct. 




$\mathrm{B}$

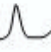

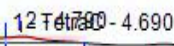

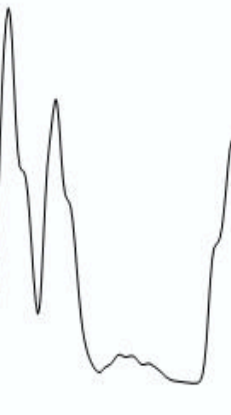

Figure 2. (A) Clear, symmetric peaks of tetracycline (TC) and chlortetracycline (CTC) were seen with the Acclaim ${ }^{8}$ RSLC C18 PA2 column. (B) The Acclaim ${ }^{\circledR} 120 \mathrm{C} 18$ column produced slightly less distinct and symmetric peaks.

Table 2. Antibiotic recovery (\%) associated with sample size.

\begin{tabular}{|c|c|}
\hline Sample Volume (mL) & Antibiotic Recovery $\left.^{\mathbf{1}} \mathbf{( \% )}\right)^{\mathbf{2}}$ \\
\hline 100 & 12.9 \\
\hline 200 & 12.5 \\
\hline 300 & 15.2 \\
\hline 400 & 15.1 \\
\hline 500 & 13.9 \\
\hline
\end{tabular}

${ }^{1}$ Manure free sample only

${ }^{2}$ Oxytetracycline

\section{Wavelength}

Results indicated that the most distinct peaks on the chromatograms occurred using a wavelength of $356 \mathrm{~nm}$. Figure 3 shows a sample with a $20 \mu \mathrm{g} / \mathrm{mL}$ of COMBO and $1 \mathrm{mg} / \mathrm{L}$ manure at the wavelengths 230,290 , and $356 \mathrm{~nm}$. The baseline of Figure $3 \mathrm{c}$ is close to zero, and the peaks for OTC and TC are clear and defined at $356 \mathrm{~nm}$, which cannot be said of the other two wavelengths.

\section{Manure Concentration}

The recovery rates for TC and CTC were quite low across all lev els of manure concentration, averaging $0.5 \%$ for TC and $1.5 \%$ for CTC. As the concentration of manure increased, the recovery rates of OTC decreased, as seen in Figure 4. The decreasing trend does not appear in CTC. This impurity was seen in the control (manure, no antibiotics) and in OTC and TC only (manure) samples (Figure $5)$. The presence of this impurity makes determining the amount of CTC in a sample challenging.

\section{DISCUSSION}

Measurement of antibiotics in water samples containing manure, using the HPLC, was best accomplished by the following methodology.

- Mobile phase solution of acetonitrile $\left(\mathrm{C}_{2} \mathrm{H}_{3} \mathrm{~N}\right)$ with $0.05 \%$ formic acid $\left(\mathrm{C}_{2} \mathrm{H}_{4} \mathrm{O}_{2}\right)$ (best separation between OTC and TC),

- Acclaim ${ }^{\circledR}$ RSLC C18 PA2 column,

- Smaller sample volumes (more time-efficient, especially for lyophilization), and

- Wavelength of $356 \mathrm{~nm}$.

While we hypothesized that the factors mobile phase solution, HPLC column, sample volume, and wavelength would influence the measurement of antibiotics in water samples, we did not know which treatment would yield the best results for OTC, TC, and CTC.

\section{Mobile Phase Solution}

Using a mobile phase solution comprised of $0.05 \%$ formic acid in acetonitrile produced the best separation between OTC, TC, and CTC. These results agreed with other studies that found that the ability to detect antibiotics increased when using formic acid. Jia 


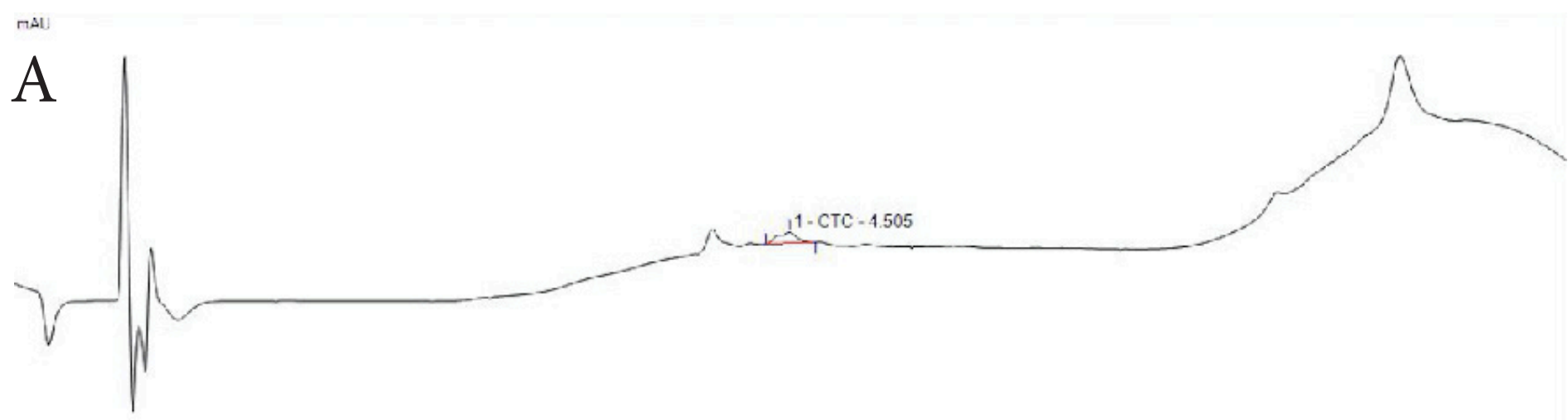

maU

B
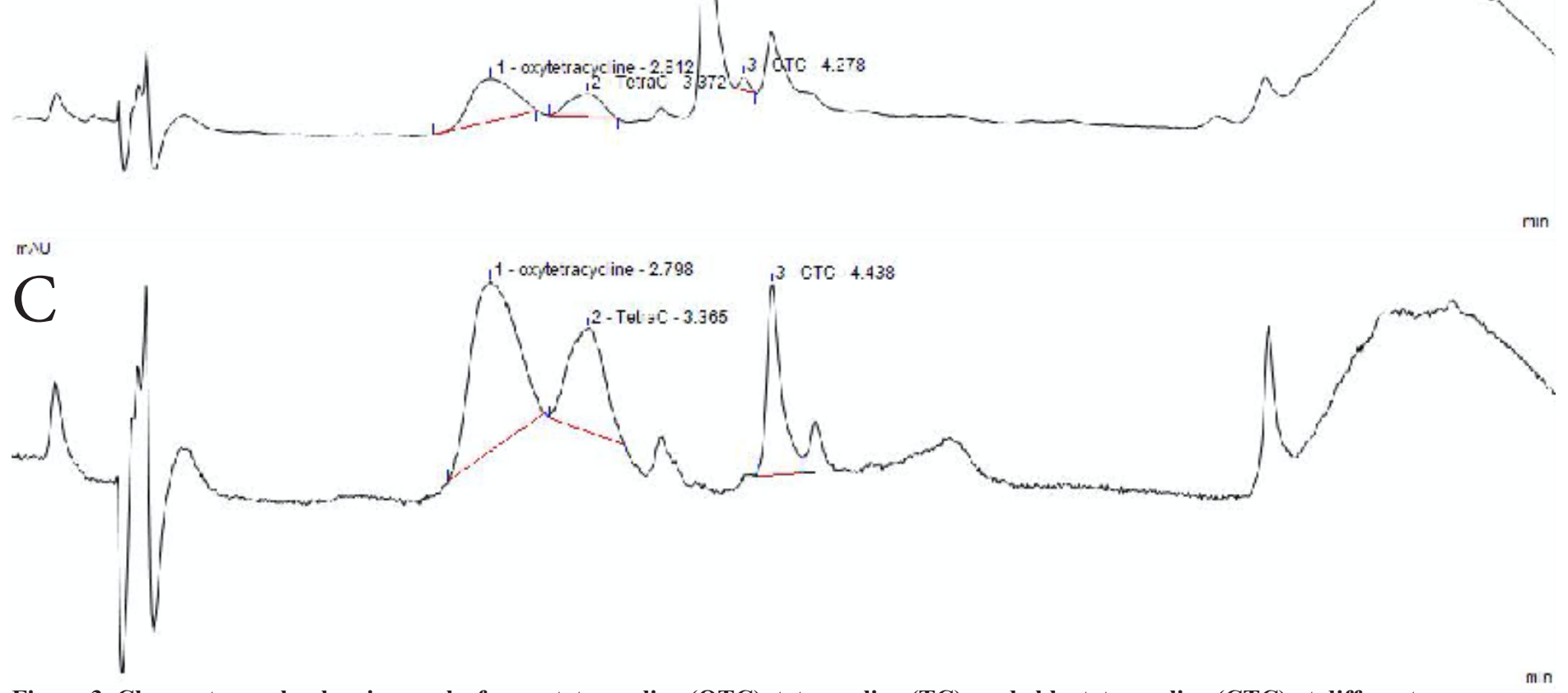

Figure 3. Chromatographs showing peaks for oxytetracycline (OTC), tetracycline (TC), and chlortetracycline (CTC) at different wavelengths. (A) $230 \mathrm{~nm}$, (B) $290 \mathrm{~nm}$, and (C) $356 \mathrm{~nm}$.

et al. (2009) examined the effect of formic acid on HPLC sensitivity in antibiotic detection and found that formic acid increased signal intensities for OTC and CTC but not TC. Suárez et al. (2007) recommended using a volatile acid mobile phase solution for detecting tectracyline compounds. The researchers examined a 1:1 (v:v) methanol to water mixture, with different percentages of formic acid (from $0.2 \%$ to $2 \%$ ) as a sheath liquid and found formic acid at $0.5 \%$ yielded the best results in terms of mass spectrometry signal intensity. Improved antibiotic identification using acetonitrile may be linked to methanol's role in TC degradation. Liang,
Denton, and Bates (1998) found that the degradation of TC is increased in methanol solutions via functional group substitutions or additions on TC. The results of this study agreed with findings from these prior studies.

\section{HPLC Column}

Of the two HPLC columns examined, separation of OTC, TC, and CTC was best when using the Acclaim ${ }^{\circledR}$ RSLC C18 PA2 column. Similar results were found by Ritorto et al. (2014) who compared the performance of the Acclaim ${ }^{\circledR} 120 \mathrm{C} 18$ and the Acclaim ${ }^{\circledR}$ 


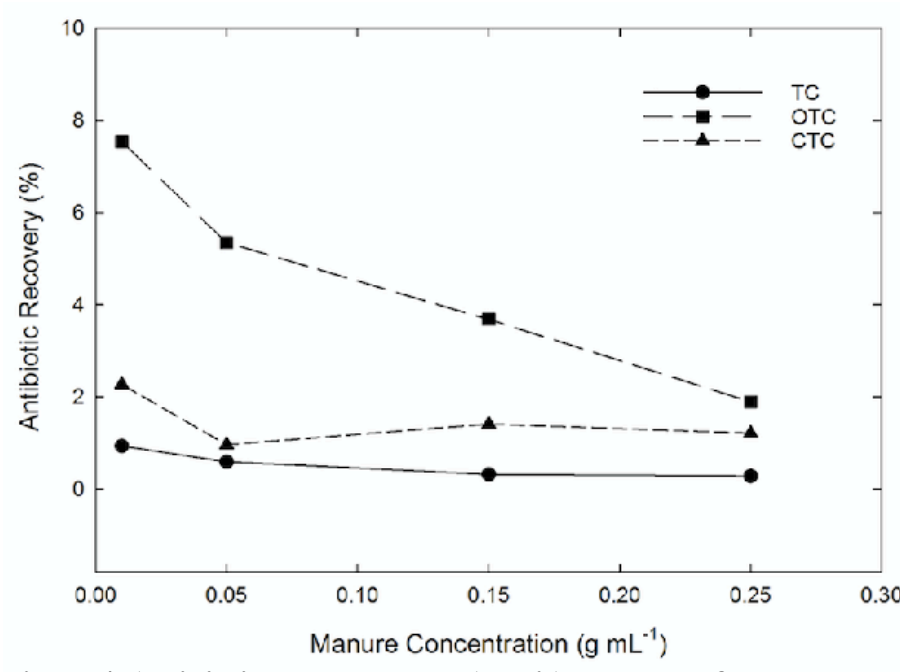

Figure 4. Antibiotic recovery rates (y-axis) decreased for oxytetracycline (OTC) as the concentration of manure ( $x$-axis) increased. No significant trends were noted for tetracycline (TC) or chlortetracycline (CTC).
RSLC C18 PA2 to separate tryptic digested proteins from cell lysate. The researchers found that the Acclaim ${ }^{\circledR}$ RSLC C18 PA2 had higher efficiencies and exhibited higher polarity of selectivity. Unlike the Acclaim ${ }^{\circledR} 120 \mathrm{C} 18$, the Acclaim ${ }^{\circledR}$ RSLC C18 PA2 is compatible with $100 \%$ aqueous environments and has a wider $\mathrm{pH}$ range (1.5-10.0) (Thermo Fisher Scientific Inc., 2016). HPLC columns are stable over a specific $\mathrm{pH}$ range. The presence of manure can influence $\mathrm{pH}$ levels in streams, though such waters are likely to have a pH range between 4 and 8 (Harden, 2015). Haghedooren et al. (2008) examined the performance of 65 reversed-phase liquid chromatographic (RP-LC) C18 columns, including the Acclaim $120 \mathrm{C} 18$ but not the Acclaim ${ }^{\circledR}$ RSLC C18 PA2, to separate antibiotics, one of which was TC, from impurities. The Acclaim $120 \mathrm{C} 18$ was a lower performing column for separation of TC.

\section{Wavelength}

Acquiring the most distinct peaks at $356 \mathrm{~nm}$ agreed with results from other studies. Ng and Linder (2003) reported minimal differences in maximum peak absorption between TC, OTC, and CTC, with wavelengths of 369,358 , and $374 \mathrm{~nm}$, respectively. Li-

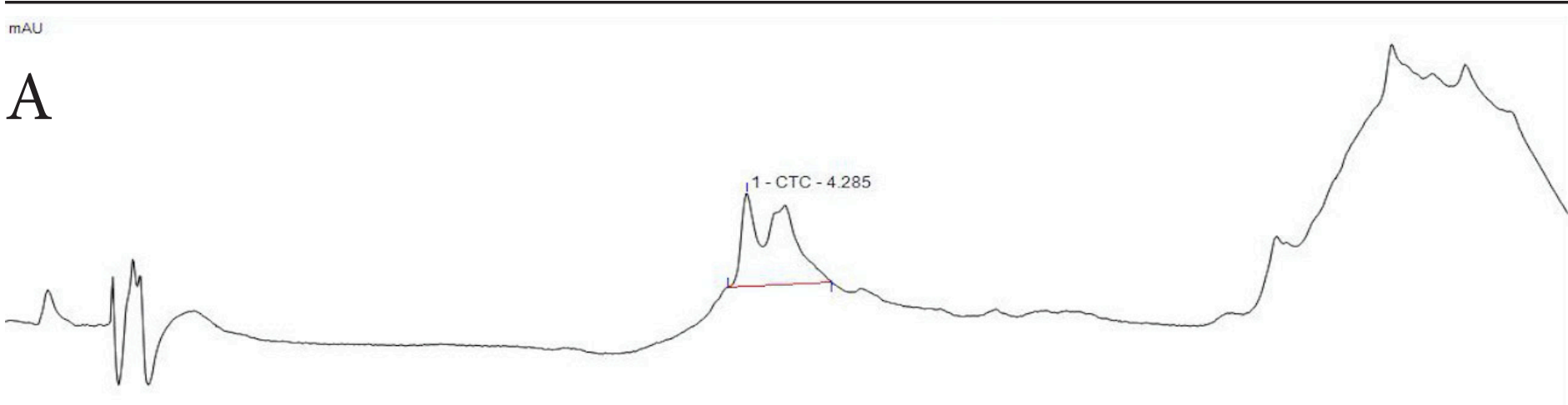

mais

B

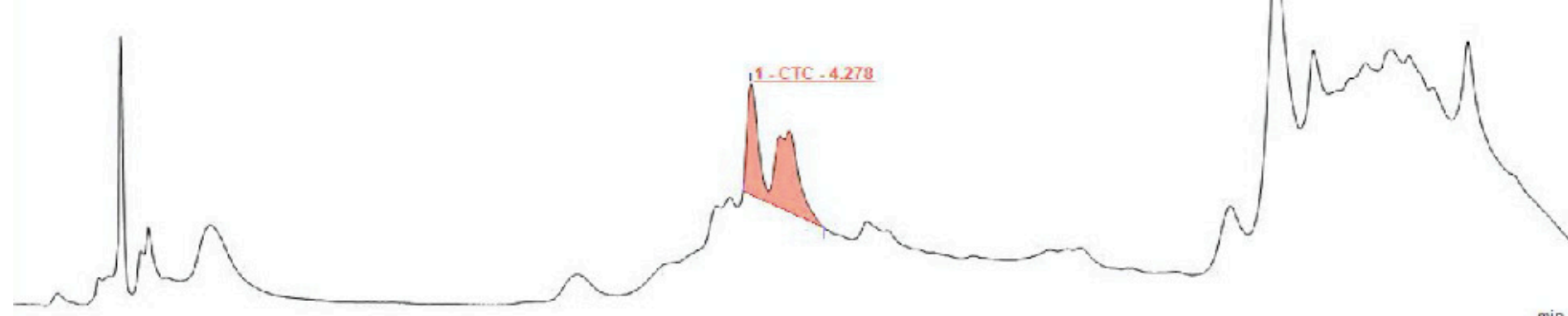

Figure 5. (A) This chromatogram shows the control, which contained manure and deionized water. (B) The impurity in the control peaks at the same time as chlortetracycline (CTC), making it difficult to discern the CTC in the CTC spiked sample. 
ang et al. (1998) found peak absorbance of TC standards mixture at $269 \mathrm{~nm}$ and peak absorbance of the degraded TC sample (e.g. OTC, CTC, and other such components) at 303 and $338 \mathrm{~nm}$. Kay et al. (2005) used a wavelength of $355 \mathrm{~nm}$ for OTC. The agreement of our findings with these studies is viewed as positive. Our methodology, with respect to the other factors examined, differed from these studies. Our results confirmed that a wavelength of $356 \mathrm{~nm}$ is appropriate for tetracycline antibiotic detection.

\section{Manure Concentrations}

The actual amount of manure in the sample impacted antibiotic recovery rates. Higher manure concentrations yielded significantly lower antibiotic recovery rates for OTC (Figure 4). The reason for this relationship is not known but possibly related to affinity for OTC to bind to manure (Loke, Tjørnelund, \& HallingSørensen, 2002). The addition of larger amounts of manure to the water samples would mean more potential for OTC-manure binding. Manure concentrations did not have a significant effect on TC and CTC recovery rates. The low levels of recovery of antibiotics from these manure-laced samples are concerning and indicate the methodology requires further refinement. We hypothesize that an impurity, possibly chloride, in swine manure is appearing at the same time as the CTC in the chromatograph, and thus is influencing this result.

\section{Secondary Sample Preparation Step (Filtration)}

Additional work is needed to evaluate the benefits of a secondary filtration step on antibiotic recovery rates. If these constraints were not present, additional sample analyses would improve our ability to draw more definitive conclusions regarding the effect of a secondary filtration on antibiotic recovery rates. We could conclude that the method of secondary filtration chosen must consider the time allotted for the study. While lyophilization takes several days, it is a process that can be left unattended. In contrast, SPE can be done immediately; however, the process of pulling a sample through the cartridges at $2 \mathrm{~mL} / \mathrm{min}$ is very time-consuming. For example, a $100 \mathrm{~mL}$ sample required 50 minutes to filter while a $500 \mathrm{~mL}$ sample required over 4 hours. We noted that a third filtration step may be needed when analyzing samples with high manure concentrations (e.g. $>5 \%$ by volume). However, a balance is needed between removing sufficient amounts of impurities to maximize HPLC performance and removing antibiotics. With each filtration, the potential exists to remove significant amounts of antibiotics from the sample.

\section{ACKNOWLEDGEMENTS}

The authors would like to thank the University of Kentucky's Office of Sustainability for funding the project, Brent Howard and Hoods Heritage Hogs for donating the antibiotic-free swine manure used in this study, and the entire Biosystems and Agricultural Engineering Department for their understanding when an odorous bucket of swine manure exploded in the laboratory.

\section{REFERENCES}

Baguer, A. J., Jensen, J., \& Krogh, P. H. (2000). Effects of the antibiotics oxytetracycline and tylosin on soil fauna. Chemosphere, 40(7), 751-757. doi. org/10.1016/S0045-6535(99)00449-X

Bean, T. G., Bergstrom, E., Thomas-Oates, J., Wolff, A., Bartl, P., Eaton, B., \& Boxall, A. B. A. (2016). Evaluation of a novel approach for reducing emissions of pharmaceuticals to the environment. Environmental Management, 58(4), 707-720.

Carlson, J., \& Kim, S. (2007). Quantification of human and veterinary antibiotics in water and sediment using SPE/LC/MS/MS. Analytical and Bioanalytical Chemistry, 387(4), 1301-1315. doi: 10.1007/s00216-006-0613-0

CDER (Center for Drug Evaluation and Research). (1994). Reviewer guidance: validation of chromatographic methods. Food and Drug Administration, Washington, D.C.

Cha, J. M., Tang, S., \& Carlson, K. H. (2006). Trace determination of $\beta$-lactam antibiotics in surface water and urban wastewater using liquid chromatography combined with electrospray tandem mass spectrometry. Journal of Chromatography A, 1115(1-2), 46-57. doi: 10.1016/j.chroma.2006.02.086

Davis, J. G., Truman, C. C., Kim, S. C., Ascough, J. C., \& Carlson, K. (2006.) Antibiotic transport via runoff and soil loss. Journal of Environmental Quality, 35(6), 2250-2260. doi: 10.2134/jeq2005.0348

Dolan, H. (2006). A guide to HPLC and LC-MS buffer selection. ACE HPLC Columns. Aberdeen, Scotland.

DeLaune, P. B. \& Moore, Jr., P. A. (2013). 17 $\beta$-estradiol in Runoff as Affected by VariousPoultry Litter Application Strategies. Science of the Total Environment, 444, 26-31. doi: 10.1016/j.scitotenv.2012.11.054.

Eaton, A. D., Clesceri, L. S., Greenberg, A. E., Franson, M. A. H., American Public Health Association, American Water Works Association, \& Water Environment Federation. (1998). Standard methods for the examination of water and wastewater. American Public Health Association, Washington, D.C.

Enlow, H. (2014). Evaluating sampling strategies for rainfall simulation studies and surface transport of antibiotics from swine manure applied to fescue plots. M.S. Thesis, University of Kentucky, Lexington, KY.

Haghedooren, E., Kóczián, K., Huang, S., Dragovic, S., Noszál, B., Hoogmartens, J., \& Adams, E. (2008). Finding an alternative column for the separation of antibiotics on XTerra RP using a column classification system. Journal of Liquid Chromatography \& Related Technologies, 31, 1081-1103. doi:10.1080/10826070802000509

Harden, S. L. (2015). Surface-water quality in agricultural watersheds of the North Carolina Coastal Plain associated with concentrated animal feeding operations. U.S. Geological Survey Scientific Investigations Report 2015-5080.

Hernández, F., Sancho, J., Ibáñez, M., \& Guerrero, C. (2007). Antibiotic residue determination in environmental waters by LC-MS. Trends in Analytical Chemistry, 26(6), 466-485. 10.1016/j.trac.2007.01.012

Hirsch, R., Ternes, T. A., Haberer, K., Mehlich, A., Ballwanz, F., \& Kratz. K. L. (1998). Determination of antibiotics in different water compartments via liquid chromatography-electrospray tandem mass spectrometry. Journal of Chromatography A, 815(2), 213-223. doi: 10.1016/S0021-9673(98)00335-5

Jia, A., Xiao, Y., Hu, J., Asami, M., \& Kunikane, S. (2009). Simultaneous determination of tetracyclines and their degradation products in environmental waters by liquid chromatography-electrospray tandem mass spectrometry. Journal of Chromatography A, 1216(22), 4655-4662. doi: 10.1016/j.chroma.2009.03.073

Kay, P., Blackwell, P. A., \& Boxall, A. B. A. (20005). Transport of veterinary antibiotics in overland flow following the application of slurry to arable land. Chemosphere, 59(7), 951-959. doi: 10.1016/j.chemosphere.2004.11.055

Kim, S. C. \& Carlson, K. (2007). Quantification of human and veterinary antibiotics in water and sediment using SPE/LC/MS/MS. Analytical and Bioanalytical Chemistry, 387(4), 1301-1315. doi: 10.1007/s00216-006-0613-0

Kolpin, D. W., Furlong, E. T., Meyer, M. T., Thurman, E. M., Zaugg, S. D., Barber, L. B., \& Buxton, H. T. (2002). Pharmaceuticals, hormones, and other organic wastewater contaminants in US Streams, 1999-2000: A national reconnaissance. Environmental Science \& Technology, 36, 1202-1211. doi: 10.1021/ 
es011055j

Kumar, K., Gupta, S. C., Chander, Y., \& Singh, A. K. (2005). Antibiotic use in agriculture and its impacts in the terrestrial environment. Advances in Agronomy, 87, 1-54. doi: 10.1016/S0065-2113(05)87001-4

Liang. Y., Denton, M. B., \& Bates, R. B. (1998). Stability studies of tetracycline in methanol solution. Journal of Chromatography A, 827(1), 45-55. doi: 10.1016/S0021-9673(98)00755-9

Lin, C. H., Lerch, R. N., Goyne, K. W., \& Garrett, H. E. (2011). Reducing herbicides and veterinary antibiotic losses from agroecosystems using vegetative

buffers. Journal of Environmental Quality, 40(3), 791-799.

Lindberg, R., Jarnheimer, P. A., Olson, B., Johansson, M., \& Tysklind, M. (2004).

Determination of antibiotic substances in hospital sewage water using solid phase extraction and liquid chromatography/mass spectrometry and group analogue internal standards. Chemosphere, 57(10), 1479-1488. doi: 10.1016/j. chemosphere.2004.09.015

Lindsey, M., Meyer, M., \& Thurman, E. (2001). Analysis of trace levels of sulfonamide and tetracycline antimicrobials in groundwater and surface water using solid-phase extraction and liquid chromatography/mass spectrometry. Analytical Chemistry, 73(19), 4640-4646. doi: 10.1021/ac010514w

Loke, M. L., Tjørnelund, J., \& Halling-Sørensen, B. (2002). Determination of the distribution coefficient $(\log \mathrm{Kd})$ of oxytetracycline, tylosin $\mathrm{A}$, olaquindox and metronidazole in manure. Chemosphere, 48(3): 351-361.

Ng, K., \& Linder, S. W. (2003). HPLC separation of tetracycline analogues: comparison study of laser-based polarimetric detection with UV detection. Journal of Chromatographic Science, 41, 460-466.

NRCS (Natural Resource Conservation Service). (2012). Conservation practice standard nutrient management (590). Retrieved from https://www.nrcs.usda. gov/Internet/FSE_DOCUMENTS/stelprdb1046896.pdf.

Ritorto, M., Ewan, R., Perez-Oliva, A., Knebel, A., Buhrlage, S.J., Wightman, M., Kelly, S.,Wood, N., Virdee, S., Gray, N., Morrice, N., Alessi, D., \& Trost, M. (2014). Screening of DUB activity and specificity by MALDI-TOF mass spectrometry. Nature Communications, 5, 4763. doi: 10.1038/ncomms5763

Shimadzu. Tips for Practical HPLC Analysis: Separation Know-how. Shimadzu. LC World Talk Special Issue Volume 2. Tokyo, Japan. Retrieved from http:// www.shimadzu.eu/sites/default/files/Tips_for_practical_HPLC_analysisSeparation_Know-how.pdf.

Shore, S. \& Pruden, A. (Eds.). (2009). Hormones and pharmaceuticals generated by concentrated animal feeding operations (Vol. 1). Springer, New York, NY.

Suárez, B., Santos, B., Simonet, B. M., Cárdenas, S., \& Valcárcel, M. (2007). Solid-phase extraction-capillary electrophoresis-mass spectrometry for the determination of tetracyclines residues in surface water by using carbon nanotubes as sorbent material. Journal of Chromatography A, 1175(1), 127-132. doi: 10.1016/j.chroma.2007.10.033

Thermo Fisher Scientific Inc. (2016). Reversed-Phase LC Columns. Retrieved from http://www.dionex.com/en-us/products/columns/lc/reversed-phase/lp$71740 . \mathrm{html}$

Tolls, J. (2001). Sorption of veterinary pharmaceuticals in soils: a review. Environmental Science and Technology, 35(17), 3397-3406. doi: 10.1021/es0003021

Tong, L., Wang, Y., \& Zhu, K. (2009). Analysis of veterinary antibiotic residues in swine wastewater and environmental water samples using optimized SPE-LC/MS/MS. Chemosphere 74(8), 1090-1097. doi: 10.1016/j.chemosphere.2008.10.051

Tylova, T., Olsovska, J., Novak, P., \& Flieger, M. (2010). High-throughput analysis of tetracycline antibiotics and their epimers in liquid hog manure using ultra performance liquid chromatography with UV detection. Chemosphere, 7(4), 353-359. doi: 10.1016/j.chemosphere.2009.11.020

Yang, S., Cha, J., \& Carlson, K. (2005). Simultaneous extraction and analysis of 11 tetracycline and sulfonamide antibiotics in influent and effluent domestic wastewater by solid-phase extraction and liquid chromatography-electrospray ionization tandem mass spectrometry. Journal of Chromatography A, 1097(1-2), 40-53. doi: 10.1016/j.chroma.2005.08.027

Yang, W., Moore, I. F., Koteva, K. P., Bareich, D. C., Hughes, D. W., \& Wright, G. D. (2004). TetX is a flaven-dependent monooxygenase conferring resistance to tetracycline antibiotics. The Journal of Biological Chemistry, 279(50),
5234652352. doi: 10.1074/jbc.M409573200

Ye, Z., Weinberg, H. S., \& Meyer, M. T. (2006). Trace analysis of trimethoprim and sulfonamide, macrolide, quinolone, and tetracycline antibiotics in chlorinated drinking water using liquid chromatography electrospray tandem mass spectrometry. Analytical Chemistry, 79(3), 1135-1144. doi: 10.1021/ac060972a 